\title{
GRUPO DE ESTUDOS E PESQUISA EM INFORMÁTICA NA EDUCAÇÃO (GEPIED/UFS/CNPq)
}

\section{Objetivo(s) do Grupo}

Missão: Desenvolver estudos, pesquisas e produtos digitais envolvendo a problemática da utilização da Informática na Educação visando o desenvolvimento econômico e social do Brasil.

Visão: Ser reconhecido como um grupo de referência em Sergipe e no Brasil no campo da Informática Educativa promovendo estudos, pesquisas e trabalhos de extensão de relevância acadêmica e social.

\section{Universidade participante}

Departamento de Computação - DCOMP; Universidade Federal de Sergipe - UFS

\section{Pesquisadores/Desenvolvedores envolvidos}

Coordenador: Prof. Dr. Dr. Henrique Nou Schneider

Prof $^{a}$ Dr $^{\mathrm{a}}$. Maria Augusta Silveira Netto Nunes

Prof. Dr. Gláucio José Couri Machado

Pesquisadores Mestres: Ártemis Bareto de Carvalho; Christiano Lima Santos; Daniele Santana de Melo; Elissandra Silva Santos; Geovânia Carvalho; Givaldo Almeida dos Santos; Sheilla Silva da Conceição.

Mestrandos: Adriana Alves Novais Souza; Diego Santana Silveira; Max Augusto Franco Pereira.

Iniciação Científica: Ana Paula Santos Soares; Carlos Gabriel Santos Nunes.

\section{Parceiros:}

○ Comissão Especial de Informática na Educação da Sociedade Brasileira de Computação (CEIE/SBC);

- Departamento de Ciência da Computação do Instituto de Matemática e Estatistica (IME/USP);

- Núcleo de Complexidade e Cognição (NUCOG/UFSC);

- Programa de Pós-Graduação em Informática (PPGI/UFAM);

- Programa de Pós-Graduação em Educação (PPGED/UFS);

- Grupo de Pesquisa em Educação, Cultura e Corporeidade (GEPECC/UFS);

- Grupo de Pesquisa em Tecnologias Intelectuais, Mídias e Educação Contemporânea (SEMINALIS/UFS/CNPq);

- Museu de Arqueologia de Xingó (MAX/UFS);

- Serviço Nacional de Aprendizagem Comercial - Sergipe (SENAC/SE);

- Serviços Gráficos de Sergipe (SEGRASE);

- Colégio Graccho (Aracaju/SE).

\section{Principais projetos (concluídos/em andamento) e fomentos recebidos}

- Coordenação do $22^{\circ} \mathrm{SBIE}-17^{\circ}$ e WIE - 2011;

- Organização do I, II, III e IV Ciclo de Conferências TIC \& Educação (2011; 2012; 2013 e 2014).

○ 2014 - Dmitry - Uma customização do Moodle para a gestão da Aprendizagem Baseada em Projetos: PIBIC/CNPq - Área: Engenharia de Software;

- 2013 - Uma interface Moodle que suporte colaboração no processo de ensino e aprendizagem online: PIBIC/CNPq - Área: Arquitetura de Sistemas de Computação;

- 2012 - Criando um template otimizado para os serviços do Portal UFS visando a usabilidade e acessibilidade via dispositivos móveis: PIBIC/CNPq - Área: Ciência da Computação;

- 2012 - Desenvolvimento de metodologias de extração de perfil psicológico em/para dispositivos móveis: PIBIC/CNPq - Área: Ciência da Computação;

- 2012 - Uma extensão ao Moodle para identificar o perfil de aprendizagem dos alunos de EaD: PIBIC/CNPq - Área: Engenharia de Software. 